\title{
Framing Sustainability in Public Procurement by typologizing Sustainability Indicators - The Case of Switzerland
}

\begin{abstract}
Purpose - Sustainable Public Procurement (SPP) lacks common means for its operationalization within legislative latitudes. Through the translation of Sustainability Indicators (SIs) from CSR and corporate sustainability reporting into the needs of SPP we aim to support the framing process of sustainability in public procurement. We do so along the case of Switzerland.

Design/methodology/approach - We perform a typological analysis of well established Sls from CSR reporting to propose a criteria framework for SPP. Secondly, we test the framework's usability and feasibility with an expert online survey conducted in the Swiss SPP landscape.
\end{abstract}

Findings - We propose ten generic criteria to frame the operationalization of SPP. Furthermore, public procurement experts from Switzerland evaluate the SPP framework as useful and feasible.

Practical Implications - The generic SPP criteria framework provides a common ground for the operationalization of SPP building on existing sustainability performance measurement knowledge as well as a frame to operationalize sustainability measurements for public tender processes.

Research limitations and future research - A limitation of the study can be seen in its deductive approach. Thus, it rather complements recent inductive approaches of SPP type and frame developments than replacing them. Future studies can further refine the understanding and operationalization of sustainability in public procurement.

Originality - To our best knowledge this is the first attempt to directly translate established Sls from sustainability reporting into public procurement to frame SPP and to use existing sustainability measurement knowledge for its operationalization and harmonization.

Keywords - Sustainable Public Procurement, SPP, Sustainability, CSR, SIs, CSR Reporting 


\section{Introduction}

Although the literature on sustainable public procurement (SPP) is increasing, the topic still lacks a commonly agreed upon and formalized frame to measure and compare sustainability. The literature is specialized in both green and social procurement (for an overview and research stages see Cheng et al 2018) and national legislators increasingly promote SPP, particularly following guidelines from transnational organizations like WTO (2012, 2015). The introduced and upcoming revised public procurement legislations mandate the comparison of sustainability in public procurement tender processes, as the Swiss case illustrates. However the lawmakers cannot deliver all the means to do so (ARE, 2018; BAFU, 2018; Prier et al., 2016).

The new legislations for public procurement follow the revised General Procurement Agreement (GPA) of the WTO which aims to foster sustainability in public procurement (Knebel et al., 2019; WTO, 2012, 2015). Some scholars even proclaim a paradigm shift in public procurement towards sustainability (Arrowsmith and Anderson, 2011a; Dragos and Neamtu, 2014). Furthermore, international guidelines for the implementation of sustainable procurement like the recently introduced ISO 20400 lack clear common means to measure and compare sustainability (ISO, 2017; UNEP, 2012). With the research presented in this paper we aim to contribute to the closing of this gap.

Recent research identifies a high implementation degree of SPP but a lack of structure and common understanding of SPP. Hence, researchers currently search for types and frames to harmonize SPP (Grandia and Kruyen, 2020; Grandia and Meehan, 2017; Sönnichsen and Clement, 2020).

The debate in the SPP research focused mainly on the assessment of drivers and barriers of SPP (Brammer and Walker, 2011; Gelderman et al., 2015; Grandia and Kruyen, 2020; Prier et al., 2016). However, it tended to neglect a focus on the overcoming of barriers (Meehan and Bryde, 2011). Recent studies show a change in this theoretical approach and aim to work towards an all including common definition, frame and types of SPP (Grandia and Kruyen, 2020; Grandia and Meehan, 2017). With our research we follow this change in research and aim to support the framing of SPP in order to advance its implementation. So, we suggest to use sustainability performance measurements stemming from proven Sls in tender processes as also suggested by other researchers (Alhola et al., 2019). Hence, we filter out the essence of existing sustainability performance measurement from sustainability reporting, build types for SPP and construct with these types a frame for SPP. In doing so we translate existing knowledge from proven and existing Sls into SPP. Thus, we follow Meehan and Bryde's recommendations, first by taking successful experiences from other areas of sustainability implementation, secondly by developing a small and clear set of generic criteria for SPP, while focusing on triggers to overcome barriers of SPP (Meehan and Bryde, 2011).

With the sampling of a raw data set of 665 commonly currently used SIs we gather the existing knowledge of sustainability performance measurement. Afterwards, we filter out their essence and derive SPP generic criteria using the qualitative method of a typological analysis. In a third step, we validate the SPP frame in an online survey with Swiss public procurement experts regarding their usability and feasibility for the Swiss context.

As a result, ten derived generic criteria build a framework for SPP and enable its immediate and structured operationalization. Furthermore, Swiss procurement experts validate the SPP frame and confirm its usability and feasibility.

These findings contribute to the theory of SPP a frame for its operationalization and complement the current searches for SPP types out of SPP data (Grandia and Kruyen, 2020). 
The paper is structured in three parts. The first part outlines current debates in sustainability measurement and SPP. The second part explains the methodological approach including results and findings. The third part outlines practical implications, provides a discussion of the presented research, and depicts limitations and future research. 


\title{
SPP and the maturation of the field
}

\author{
Social and Green Procurement
}

Public procurement formalizes purchasing decisions in supply chain of public buyers based on predefined product and service criteria with regard to cost. With the increase of global challenges and harmful effects of consumption the question of sustainability is on the rise, particularly regarding environmental issues. Hence, green public procurement (GPP) is among the most formalized public procurement practices going beyond mere economic logics incorporating green issues, respectively reducing adverse effects of unsustainable purchasing decisions (Cheng et al. 2018). However, environmental issues not entirely cover aspects of sustainability, understood here as triple bottom line of economic, environmental and societal issues. Therefore, social sustainability (that is respect for human rights, integrity, anti-corruption, fair work etc.) are also increasingly dealt with when advancing public procurement. In addition to the well-established segment of GPP this study therefore takes a more holistic view regarding sustainability including also social sustainability. The term suggested here to include all three dimensions of sustainability, is therefore SPP, in line with Caranta (2010) or Knebel et al. (2019). The key learnings from GPP, that also apply to SPP are foremost spill-over effects on innovation (Cheng et al 2018) particularly for environmental issues, but also for social issues.

\section{The way of SPP and the Swiss Context \\ SPP and lack of a common understanding}

Public procurement laws require the implementation of sustainability in tender processes following the revised GPA to foster sustainability as well as the EU directive 2014/24/E (European Union, 2014; WTO, 2015). Recent studies approach the question of how to ideally compare sustainability in public procurement (Alhola et al., 2019; Bernal et al., 2019; Grandia and Kruyen, 2020; Grandia and Meehan, 2017; Grandia and Voncken, 2019; Sönnichsen and Clement, 2020).

So far, new laws like the recently introduced revised BÖB in Switzerland or international guidelines like the ISO 20400 lack a clear usage indication of sustainability comparison in public procurement. Meanwhile researchers spotted an higher than expected usage of sustainability implementations in tender procedures in Belgium (Grandia and Kruyen, 2020). However, the same study also emphasizes the different approaches and understandings of sustainability in the profession as well as a prevalent implementation degree of the environmental dimension of sustainability (Grandia and Kruyen, 2020; Sönnichsen and Clement, 2020). Other studies identify the need of all sustainability dimensions present in SPP tender processes, especially the neglected social dimension (Bernal et al., 2019; Grandia and Meehan, 2017; Grandia and Voncken, 2019). Also recent studies from political bodies in Switzerland gain similar insights (ARE, 2018; BAFU, 2018; Steiner, 2020).

The expression "sustainability" itself remains heavily debated because of its broadness and abstractness. Thus, it creates confusion and cynicism but also environmental, social, and economic change (Dragos and Neamtu, 2014). The concept of sustainability in its modern meaning rose in the 70's as response to the massive industrial growth and mass consumption, as well as rising complexities and dependencies within a globalization process causing severe impacts on the environment and societies worldwide (Dragos and Neamtu, 2014; Helbing, 2013; Knebel and Seele, 2015). Despite many approaches to define sustainability, for the purpose of this paper we follow the most known fundamental definition from the Brundtland Report which defines sustainability as development which meets the 
needs of the present without compromising the ability of future generations to meet their own needs (World commission on environment and development, 1987).

Academics asses the theoretical body of public procurement and SPP as expandable but accredit it a rising interest in research (Brammer and Walker, 2011; Gelderman et al., 2015; Preuss, 2009). Researchers pin this development on the continuously appearing major scandals in public procurement (Thai, 2001, 2008), as well as on the cognizance of public procurement as key component towards sustainability. The attribute "key component towards sustainability" derives from the possibility of cascading supply chain effects globally and bases on the purchasing force of trillions of dollars flowing through the mechanisms of publicly procured goods and services worldwide per year with great impact on the economy (Knebel et al., 2019; Smith and Terman, 2016; The World Bank, 2016). The idea to use the forceful function of public procurement as tool to achieve economic, social and other objectives, reaches back centuries (Grandia and Meehan, 2017; McCrudden, 2004; Smith and Terman, 2016; Thai, 2001). At the same time, governments use public procurement as foreign policy tool to achieve objectives like national economic stabilization and development, also by preferring national and local firms over firms from other countries in a protectionist way (Thai, 2001).

For the further course of this paper, we refer to public procurement as acquisition of goods and services by government of public sector organizations (Uyarra and Flanagan, 2010). At the same time we acknowledge the different factettes in the theoretical field (Brammer and Walker, 2011; Gelderman et al., 2015; Preuss, 2009) and understand within this definition public procurement as a broad field, involving more than the procurement process, but also its potential as a policy tool, its importance for government efficiency, its impacts on innovation and development, as well as the strategic implications it brings along (Flynn and Davis, 2014; Koala and Steinfeld, 2018; Patrucco et al., 2017; Thai, 2008).

Adding sustainability to public procurement, we understand public procurement as sustainable when it enfolds the economic, environmental and social dimensions in all public purchases (Brammer and Walker, 2011; Knebel et al., 2019; McCrudden, 2004). Hence, we acknowledge the existence of various forms of understandings and even naming of SPP like green public procurement, green purchasing, sustainable supply chain management amongst many more (Grandia and Kruyen, 2020). These understandings of SPP like "Green Public Procurement", next to many other names and definitions in the public and private sector, deal only with the environmental sustainability dimension (Brammer and Walker, 2011; Bratt et al., 2013; European Commission, 2017; Grandia and Kruyen, 2020; Preuss, 2009). Recent studies identified a reflection of these definitions in the actual implementation of sustainability in public procurement predominantly focusing only on the environmental dimension (Grandia and Kruyen, 2020). This paper picks up on this issue and aims to frame and harmonize these various approaches in order to generate a clear understanding of SPP enfolding all three sustainability dimensions environmental, social and economic. Thus, we follow researchers who call for SPP that includes all three sustainability dimensions, especially the rather neglected social dimension (Grandia and Meehan, 2017; Grandia and Voncken, 2019; Steiner, 2017). While present research aimed to derive SPP types and frames inductively out of current sustainability implementation attempts (Grandia and Kruyen, 2020; Grandia and Voncken, 2019) we enrich these approaches by deductively derive SPP types from realms outside of SPP. In doing so we filter and derive SPP types to measure and compare sustainability from proven Sls in sustainability and CSR reporting. The definitions and various approaches of sustainability entering public procurement call for a common ground and harmonization to further advance SPP theory and implementation (Grandia and Kruyen, 2020; Grandia and Meehan, 2017; Meehan and Bryde, 2011; Prier et al., 2016). The fact that the public procurement market represents the largest business 
sector in the world emphasizes the importance and possibilities of the call for a common understanding (OECD, 2015; The World Bank, 2016).

\section{Searching for types and frames of SPP in Switzerland}

Recently introduced SPP laws like the BÖB in Switzerland cannot guarantee the implementation of SPP. SPP research identified major barriers like financial constraints, lack of knowledge or motivation (Grandia and Kruyen, 2020). These found-out barriers also come into play in Switzerland (ARE, 2018; BAFU, 2018).

The roots of sustainability in public procurement in Switzerland reach far back into the 90's of the last century. The Swiss law for public procurement, federal act of public procurement (FAPP), enfolded the possibility to include criteria concerning the environment, gender equality and working conditions in 1996 (FAPP Art. 8, Art. 21) (ARE, 2018). A further strong root reaches back and into the Federal Office for the Environment of Switzerland (FOEN) as part of the league of ecological procurement (IGÖB).

The available guides, indicators and platforms for SPP internationally and national in Switzerland spring like mushrooms in many different places (BAFU, 2018). At one side, the spring of guides and tools proves an upswing of sustainability matters and sustainability sensitization in public procurement, on the other side it proves its current dilemma by lacking a harmonization and clarity for comparability and easy access (BAFU, 2018).

The diversification of available tools and guides serves as innovation pool but reveals also barriers towards SPP. Stakeholder conflicts describe one of these barriers. Hereby, stakeholder conflicts stand for the various and interacting pressures on the public procurement system. These pressures result in trade-offs between sustainability forces, and other potentially conflicting stakeholder goals like market structure, industry development, national protectionism, and the protection of national jobs (Gelderman et al., 2015; Thai, 2001). This phenomenon also describes a major difference to sustainable procurement in the private sector which despite several efforts remains heavily profit driven to please most of all shareholder interests. SPP on the other side sits in a mediating position between politicians, the public, citizens, taxpayers, unions, and the bureaucratic body (Gelderman et al., 2015; McCue and Prier, 2008; Thai, 2008). In this complex situation research revealed that professionals tend to make the resulting trade-offs between various stakeholder goals in favor of their department managers (Gelderman et al., 2015). Divided loyalties, multiple masters, conflicting interests and goals describe public procurers' role, in which they aim to balance pressures and secure their own jobs (Grandia, 2015; McCue and Prier, 2008). Hence, various stakeholder pressures provoke various SPP approaches. This proves to be true also in the Swiss context as to be seen in the two most used guides one used predominantly in the French speaking part, the other in the German speaking part. Furthermore, the various involved federal departments in the development of the guides exemplify this barrier in the Swiss context (BAFU, 2018).

Stakeholder conflicts potentially cause fragmentation. Hence, scholars identified fragmentation and variation of SPP approaches as barrier on an international level (Arrowsmith and Anderson, 2011b; Brammer and Walker, 2011), on a national level (Prier et al., 2016), within public procuring organs (Grandia, 2016) and even between procurement projects of the same procuring department (Grandia, 2015). Thus, researchers recognize the need for decentralization in public procurement to meet individual requirements of each product and service. However, at the same time, their findings show a high degree of fragmentation and silo approaches caused by this decentralization (Thai, 2001). Additionally, decentralized procurement functions focus on different, varying and changing 
aspects of sustainability (Brammer and Walker, 2011; Walker and Brammer, 2009). The fragmentation and decentralization causes rather cautious and experimental approaches to SPP without overall strategies or goals (Prier et al., 2016). The Swiss case exemplifies these fragmentations in the legislative dimension, the organizational dimension, and strategic dimension with its consequences. Figure 1 provides an overview of the strategic and organizational dimension of SPP in Switzerland.

Furthermore, Switzerland's federal structure fragments public procurement legislation into all levels and bodies of law. The World Trade Organization's Agreement on Government Procurement (GPA), the bilateral agreement between Switzerland and the European Union (EU) and the European Free Trade Association agreement (EFTA), frame Switzerland's obligations internationally. Nationally several bodies of law frame public procurement in Switzerland, complicated through differing federal and cantonal legislation (Steiner, 2020), accompanied by legal acts all over the legislative dimension containing traces of SPP law (ARE, 2018). Similar to the fragmentation of public procurement law, the political organization of public procurement locates in several federal departments and organs.

Figure 1 visualizes the organization of public procurement on a federal level in Switzerland. It shows the leading function within the Federal Department of Finance (FDF) in form of the Federal office for buildings and logistics (FOBL) and public procurement controlling. Further two main organs develop the strategic direction of public procurement in Switzerland. On one side the Swiss Federal Procurement Conference (FPC) and on the other side the coordination conference of construction and buildings (KBOB). The FPC defines their area of competence in services and goods, the KBOB defines their area of competences in construction and buildings. While the FDF holds all leading public procurement functions and organs, the Federal Department of the Environment, Transport, Energy and Communications (DETEK) leads the most of involved departments and offices.

Consistent with the division in two competence areas in public procurement, two units develop strategies towards SPP. Under the lead of the FPC the unit sustainability (Fachgruppe Nachhaltigkeit) works towards SPP in goods and services. And on the other side, under the lead of the $\mathrm{KBOB}$, the unit sustainable construction (Fachgruppe Nachhaltiges Bauen) works towards SPP in construction and buildings. The biggest and financially most powerful organizations related to public procurement, the Swiss Railway (SBB) and the Swiss Post (Schweizerische Post), both property of the community, sit as observers in one of the groups. Both groups meet four times per year with overlapping but not the same members. Armasuisse, the federal office for defense procurement, sits as only department in all groups and organs. 


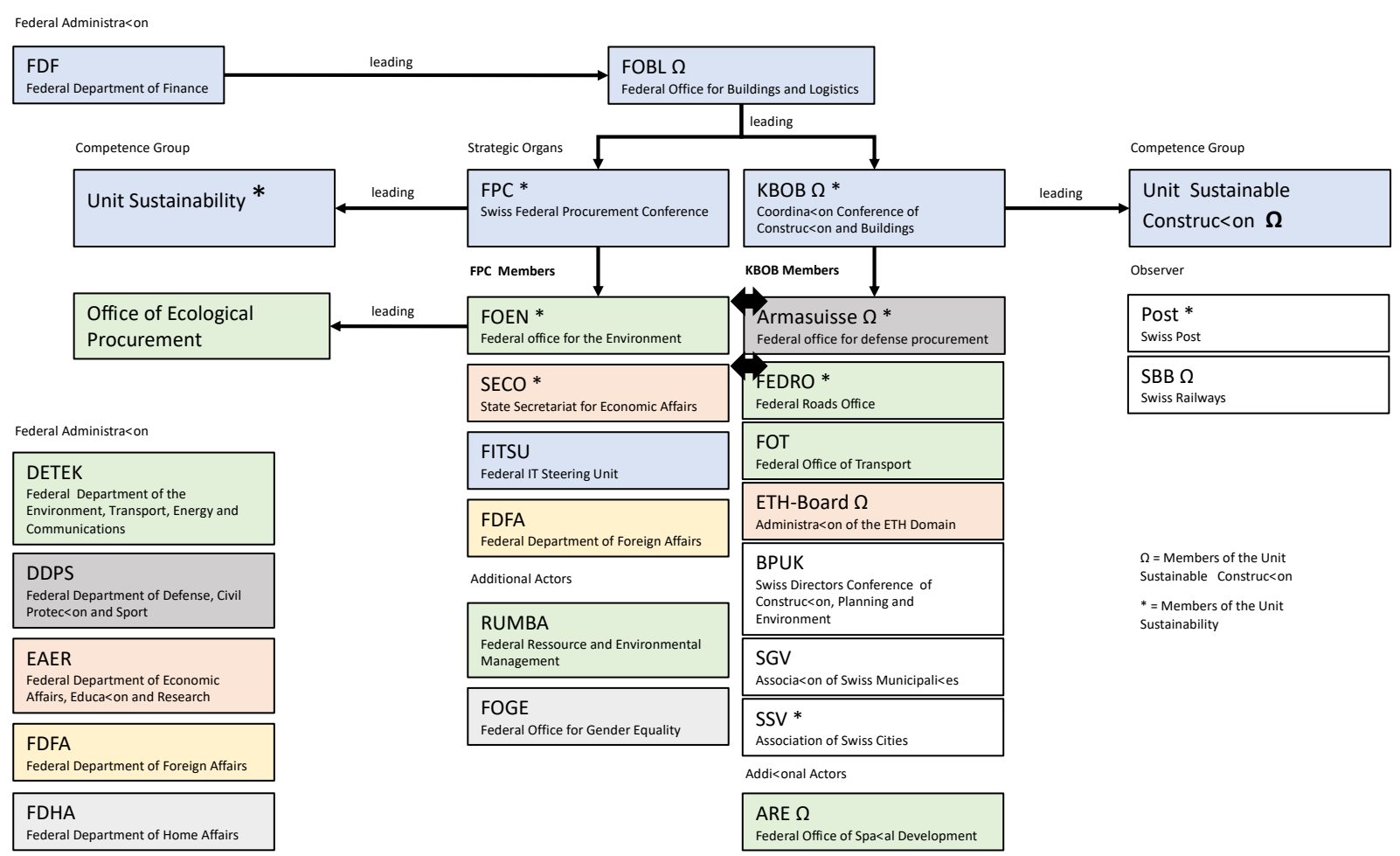

Figure 1: Organizational fragmentation of Switzerland's SPP approach

Overall the Swiss case illustrates how fragmentation and different interests result in varying understandings of SPP producing silo SPP approaches instead of a common harmonious SPP frame (ARE, 2018; BAFU, 2018; Steiner, 2020). This paper aims to harmonize and frame the understanding of SPP in the Swiss context.

After setting the stage of SPP and its illustration in the case of Switzerland, we proceed to the technical aspect of SPP. In doing so, we provide in the following an overview of Sls and their role in measuring sustainability performance, as well as the possibilities of their inclusion in public procurement tender processes.

\section{How to use proven SIs of CSR reporting for SPP}

Public procurement tender processes perform heavily standardized communications to compare goods and services in competitive markets. So far sustainability found its way into SPP in various forms. A recent study identified seven categories of SPP: "1) environmentally friendly procurement, 2) circular economy, 3) social return on investment, 4) ethical trade, 5) local and/or SME-oriented procurement, 6) Innovation-oriented procurement and 7) the use of sustainability labels" (Grandia and Kruyen, 2020, p. 14). SPP implementation refers to certain means like performance-based procurement, life cycle approaches, life cycle costing, Eco-labels, standards, and guidelines to compare sustainability (Alhola et al., 2019; Sönnichsen and Clement, 2020). The used criteria to compare sustainability show similarities to SIs in their methods, aim and scope. Both, SIs and sustainability criteria aim to simplify complexity and convey information to compare sustainability performance (Bell and Morse, 2018a, 2018b). Sls and sustainability criteria constitute translation tools to foster achievements of sustainable development (Bell and Morse, 2003). In doing so, they simplify 
complexity to provide guidance for all stakeholders, including procurers and politicians (Turnhout et al., 2007)

Participating companies in tender processes use already Sls to measure and report on their sustainability performance since the 90's. The approach presented in this paper suggests to use this knowledge and experience in sustainability measurement for SPP.

Scholars debate about SIs. One side sees SIs as indispensable tools, while the other side sees more problems than usage in aggregating something as complex as sustainability in simple metrics (Hinkel, 2011). They agree on the convenience indicators provide for communication processes but differ in their perception of the risk by oversimplification of complexities (Barnett et al., 2008; Morse, 2015). The simplification process of Sls results in trade-offs (Bell and Morse, 2018b). Thus, ironically, the reduction of complexity into digestible and communicable pieces, the biggest strength of Sls, comprises its biggest risk (Bell and Morse, 2018a). Some scholars even argue that aggregation is evil, as soon as it provides power to numbers that do not deserve it (Jesinghaus, 2018). Researchers agree that Sls cannot be perfect by design, because they do not contain laws of nature. At that, professionals build them with all their biases, worldviews and intentions (Bell and Morse, $2018 \mathrm{~b})$. The produced risks of Sls stem from hidden key decisions over included and excluded aggregated contents which influence results. In a next step, these influenced results determine decisions and strategies (Bell and Morse, 2018a). Thus, any indicator contains arbitrary choices, not only from the scientific realm but also from the political realm (Bravo, 2014). Hence, academics point out and warn all stakeholders using Sls to stay aware of their limitations (Bell and Morse, 2018b). This in turn also implies that Sls evolve, rise and vanish, depending on how they provide usefulness to indicate knowledge about sustainability performance and depending on the societal accepted values they carry along. No common terminology exists for Sls. So, for the purpose of this paper and the described field of research we use our own definition which derived from several existing ones (Turnhout et al., 2007) and the insights provided above: Indicators are process oriented evolving ideals reducing complexity that initiate change through standardization leading to comparability and performance measurement.

SIs and sustainability criteria in SPP face the same dynamic between diversification and comparability visible in other areas (Salathé-Beaulieu et al., 2019). Further, the traditional focus on easy comparable numbers in SPP as well as the focus on the environmental dimension which can rely on physical calculation tempts to rely on incremental changing numbers. However, current debates in the Sls development challenge the incrementalist way of measuring sustainability and call for contextuality. While incrementalists' focus on step by step improvement in conformity of an ever-growing industry without limits, contextualists look at sustainability from another angle emphasizing limits and thresholds (Baue, 2019; McElroy, 2019; Salathé-Beaulieu et al., 2019). These developments align with SPP approaches considering the context with tools like life-cycle costing. Even though SPP aims for clear comparability, contextuality of sustainability remains most important for the impact of sustainability performance measurement.

With these insights about Sls and their contextuality dynamic, the next lines depict our research question.

\section{Research Question}

By using the Swiss case as illustrative example, we ask: How to frame and operationalize SPP with existing sustainability performance measurement knowledge in the Swiss context? In order to approach this question, the next paragraphs explain the used methods. 


\section{Methodology \\ Research Design}

In order to approach the research question, we chose the following research design. Firstly, we sampled existing proven currently used Sls. Secondly, we performed a typological analysis to create ideal SPP types to frame SPP. Thirdly, we tested these translated Sls with Swiss public procurement experts in an online survey. The following figure 2 summarizes the research design.

Stage 1: Sampling

Gathering most prominent SIs currently used for sustainable performance measurement $(\mathrm{N}=665)$

Stage 2: Typological Analysis

1. Identifying an organizing framework for typology development

2. Identifying important sources of commonality and variation that occur in the data set

3. Looking within those sources of commonality and variation for patterns of similarity and difference.

4. Reconstruction of patterns of similarity and difference into ideal types or model cases

Stage 3: Expert Survey

Online-survey with Swiss Public Procurement Experts regarding the feasibility and usability of the SPP frame $(\mathrm{N}=21)$

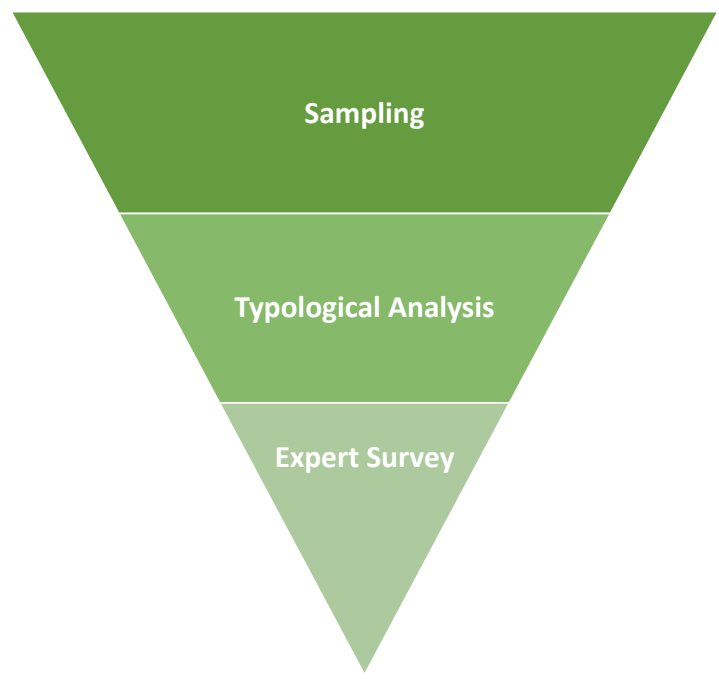

Figure 2: Overview of the used methods

\section{Sampling}

The sampling frame for this study encompassed Sls currently used in CSR reporting, in supply chain monitoring, in sustainability standards and sustainability guidelines. The collection period started in January 2019 until September 2019. We gathered the SIs of the most famous and accessible sources. These sources encompassed sustainability performance measurement from corporate reporting (GRI, 2019), supply chain rating and monitoring from frameworks like Ecovadis and the ISO 20400 (EcoVadis, 2017; ISO, 2017), target indicators from the UN to monitor the SDGs globally, also called the global indicator framework (UN DESA, 2019), further frameworks like the Global Compact (GC) (UN Global Compact, 2019), MONET 2030, the Suisse national SDG monitoring framework (BFS, 2018), the ISO 26000 Indicators on sustainability (ISO, 2010), and the UNEP sustainable consumption pattern (SCP) indicators (UNEP, 2017). The final raw data set consisted of 665 SIs $(\mathrm{N}=665)$. The following summarizes the sampling process, provides the name of the source as well as the amount of Sls retrieved from it: Global Reporting Initiative (GRI) 149 SIs, 
Global Compact (GC) 10 SIs, MONET 2030 with 106 SIs, Sustainable Development Goals (SDGs) 17 SIs, UN DESA SDG Target Indicators 244 SIs, ISO 26000 with 35 SIs, ISO 20400 with 66 SIs, EcoVadis with 21 SIs, UN SCP Indicators with 17 SIs, in total a sample with 665 SIs.

\section{Typological Analysis}

We chose as method a typological analysis because it fits to the objective to produce ideal SPP types from existing Sls. Furthermore, the method suits the approach of analyzing big raw data sets in order to identify patterns that lead into types.

Hence, typological analysis condenses raw data into brief summarizing formats linking them to research objectives. Researchers in many qualitative studies use the construction of types to gain insights into complex social realities. Some scholars describe the construction of types in detail (Given, 2008; Kluge, 2000; Suziedelis and Lorr, 1973; Thomas, 2006). A typological analysis guides the process towards a typology development. So, the derived typology bases on the underlying structure of the experiences or processes, the raw data contains (Kluge, 2000).

Thus, the primary technique of analysis consists in the construction of types from raw data (Thomas, 2006). Both, Kluge (2000) and Given (2008) describe the research process of typological analyses in four stages (Given, 2008; Kluge, 2000). Stage one, describes the development of relevant analysis dimensions (Kluge, 2000). At that, the investigator identifies an organizing framework for the typology development (Given, 2008). Stage two, instructs the researcher to grouping the cases and analysis of empirical regularities (Kluge, 2000). Hereby, once the raw data collection completes, the researcher identifies important sources of commonality and variation that occur within the structured raw data set (Given, 2008). At stage three, the investigator analyses meaningful relationships and constructs types (Kluge, 2000). Hence, the investigator hunts within the identified sources of communality and variation for patterns of similarity and difference (Given, 2008). Finally, in stage four, the researcher characterizes the constructed types of stage three (Kluge, 2000). In doing so, stage four guides the researcher to reconstruct the discovered patterns into ideal types and type characterizations (Given, 2008).

\section{Expert survey of public procurement experts}

To validate the results from the typological analysis we questioned Swiss public procurement experts in an online survey. In order to run the online survey, we used the software called "Qualtrics" and used the in the software available sorting tools. An online survey fits the objective of validating the derived SPP frame regarding its feasibility and usability. In the survey we leaned on online remote closed card sorting methods from the field of psychology which finds interest in user experience designs, especially the development of information architecture (Basri et al., 2016; Chowdhury, 2015; Mahmood et al., 2018; Schmettow and Sommer, 2016; Zimmerman and Akerelrea, 2002). At that, we used a common sorting technique asking experts to rank each generic criteria in order of their perceived importance within the field of public procurement. Further, we asked the experts to sort the generic criteria into "either" "or" categories regarding feasibility and usability. Beforehand we explained the generic criteria in detail. Figure 3 and table 1 show the results of the generic criteria ranking as well as the sorting of them. 
The fragmentation of public procurement in Switzerland as well as stakeholder pressures on public procurers as identified barriers to implement SPP also challenged the sampling of experts for a survey dealing with SPP. In order to overcome these barriers, we recruited the experts with a snowball sampling method as proven technique to reach hidden populations and experts in a certain field (Goodman, 1961). In doing so we asked 21 public procurers out of the previously described strategic organs FPC and KBOB in the federal organization of SPP in Switzerland to answer the questionnaire and pass the questionnaire link on to their professional colleagues. The collection period started beginning of September 2019 and ended with the $1^{\text {st }}$ of October 2019. In this collection period we received ten fully completed responses.

With these explanations of the used methods, the next sections outline the results and findings.

\section{Results and Findings}

We followed the above described methodological instructions for a typological analysis and gathered as raw data all proven SIs from different areas of application as the sampling section above indicates. For step one, as organizing framework, we schematically listed all sampled SIs in one data pool. Further, we gave each SI an ID and a source tag. Additionally, we copied the definitions of the Sls accordingly. Then we improved the organizing framework and used the three sustainability dimensions, environmental, social and economic as initial analysis dimension. Unexpectedly, the social dimension contains most Sls with $58 \%$ of the sample while the more reported environmental dimension encompasses only $27 \%$ of the sample. $5 \%$ of the sampled Sls do not fit the organizing framework. The following describes the environmental dimensions as organizing framework: The environmental dimension counts 177 SIs ( $27 \%$ of the sample), the economical dimension counts 66 Sls (10\% of the sample), the social dimension counts 388 Sls $(58 \%$ of the sample), not fitting this dimensioning were 34 Sls ( $5 \%$ of the sample).

As second step we identified patterns and started to group Sls accordingly. In doing so, we first excluded all SIs irrelevant for public procurement. The definitions of the Sls led to the identification of their relevance for SPP. Hence, we excluded for example indicators for general reporting practices like "message from the CEO" or "reporting period", as well as indicators concerning agriculture on a national level like "consumption of vegetables and fruits" or "risky alcohol consumption", as well as indicators with further topics outside the realm of public procurement like "maternal mortality ratio" or "malaria incidents per year". After the filtering of SPP relevant SIs, we continued with 384 Sls that contained relevance for public procurement (58\% of the initial sample) and started searching for patterns.

Later we grouped the indicators accordingly. As a result, we ended up with thirteen groups of which "Labour Rights" (55 indicators), "Human Rights" (45 indicators) and "Waste" (43 indicators) combine the most indicators (36\% of the sample). The following depicts the elaborations of step 2 and illustrate how all relevant Sls fit into one of the derived groups: Environment Protection counts 15 SIs (4\% of the reduced sample), Supply Chain counts 35 SIs $(9 \%$ of the reduced sample), Resources counts 37 SIs (10\% of the reduced sample), Stakeholder 16 SIs (4\% of the reduced sample), Governance 24 Sls (6\% of the reduced sample), Human Rights 45 SIs (6\% of the reduced sample), Corruption 19 Sls (5\% of the reduced sample), Waste 43 SIs (11\% of the reduced sample), gender 14 Sls (4\% of the 
reduced sample), Compliance 14 SIs (4\% of the reduced sample), Risks 28 SIs (7\% of the reduced sample), Labor Rights 55 SIs (14\% of the reduced sample), Investments 29 Sls ( $10 \%$ of the reduced sample).

In the fourth step, we looked for meaningful relationships and merged groups with overlaps. In doing so we continued to revise and refine the grouping. Thus, we combined for example the groups of "Labor Rights" and "Human Rights" due to their overlaps and similarities. We ended up with ten groups. Firstly, we then defined these groups and described them. Afterwards we started to construct types from them. To do so we framed group headlines. Further, we characterized those group headlines and translated respectively reworded them into public procurement. Then, we worked out explanations transforming the ideal types into SPP meta criteria. Table 1 summarizes the fourth step and the resulting framing set of meta criteria for SPP. Afterwards we operationalized the final generic criteria by choosing methods to operationalize them in SPP. Due to the scope and available space of this paper we left the operationalization out but refer to the insights of this attempt in the practical implications of this chapter.

\begin{tabular}{|l|l|}
\hline Generic Criteria & Description: This criteria asks contractors to... \\
\hline Human Rights & $\begin{array}{l}\ldots \text { approve their measures to enforce human rights and societal } \\
\text { issues. It includes measures against child labor and other forced } \\
\text { labor and measures for decent work conditions, as well as } \\
\text { bargaining powers of employees and unions. }\end{array}$ \\
\hline Supply Chain Control & $\begin{array}{l}\text { to ...approve if and how the supply chain is being controlled } \\
\text { concerning labor conditions, human rights and child labor as well } \\
\text { as environmental standards through certificates and own } \\
\text { measures. }\end{array}$ \\
\hline Environmental and Social Risks & $\begin{array}{l}\ldots \text { to provide an overview of positive and negative environmental } \\
\text { and social incidents the organization encountered. }\end{array}$ \\
\hline Gender Pay Gap & $\begin{array}{l}\ldots \text { to approve their efforts to reduce income inequality between } \\
\text { men and women. }\end{array}$ \\
\hline $\begin{array}{l}\text { Sustainability Management } \\
\text { Certification }\end{array}$ & $\begin{array}{l}\ldots \text { to show if their sustainability management is certified and how it } \\
\text { is integrated in the organization. }\end{array}$ \\
\hline Measures against Corruption & $\ldots$ to approve their efforts against corruption. \\
\hline Greenhouse Gas Emissions & $\begin{array}{l}\ldots \text { to disclose their GHG emissions of the organization as well as } \\
\text { measures and programs with actions taken to reduce the } \\
\text { emissions. }\end{array}$ \\
\hline Energy Consumption & $\begin{array}{l}\ldots \text { if and how they invested into sustainability. } \\
\text { consumption. }\end{array}$ \\
\hline
\end{tabular}




\begin{tabular}{|l|l|}
\hline Stakeholder Description & $\begin{array}{l}\ldots \text { for a description of their stakeholders, as well as how the } \\
\text { stakeholders are affecting the organization and how the } \\
\text { organization is affecting the stakeholders. }\end{array}$ \\
\hline
\end{tabular}

Table 1: Translation of ideal types into a generic criteria frame of SPP

After finalizing the SPP frame we tested its acceptability, usability and feasibility with public procurement experts as the next section describes.

Within an online survey we asked experts to sort each generic criteria either into the category "usable" or "not usable", respectively "feasible" or "not feasible". Their answers led to the results and findings summarized in the following, as well as in figure 3 . The results show the relative importance of human rights and supply chain control within the realm of public procurement in Switzerland compared to the other generic criteria in the framing set, here both generic criteria reached a mean of 2.4 respectively 2.8. The results are: Rank 1 "Human Rights" (Mean 2.40/Variance 3.24), rank 2 "Supply Chain Control” (Mean 2.8/Variance 1.96), rank 3 "Environmental and Social Risks" (Mean 4.00/Variance 3.00), rank 4 "Gender Pay Gap" (Mean 5.60/Variance 3.64), rank 5 "Sustainability Management Certification" (Mean 5.70/Variance 8.81), rank 6 "Measures against Corruption" (Mean 6.20/Variance 7.56), rank 7 "Greenhouse Gas Emissions" (Mean 6.20/Variance 9.16), rank 8 "Energy Consumption" (Mean 6.80/Variance 4.56), rank 9 "Investments in Sustainability" (Mean 7.60/Variance 4.04), rank 10 "Stakeholder Description" (Mean 6.20/Variance 5.41).

When asked about the feasibility and usability of the generic criteria, the experts rated them predominantly as both, feasible and usable. The experts reached unanimously agreement for the usability of the generic criteria "Human Rights", "Supply Chain Control", and "Green House Gas Emissions". Regarding feasibility, the experts agreed uniformly on the generic criteria "Sustainability Management Certification", "Greenhouse Gas Emissions", and "Energy Consumption" as feasible. Highlighting that, the experts also evaluated all the other framing generic criteria by a majority as usable and feasible as figure 3 illustrates. The framing generic criteria of "Investments in Sustainability" as well as "Stakeholder Description" polarized the expert opinions. 


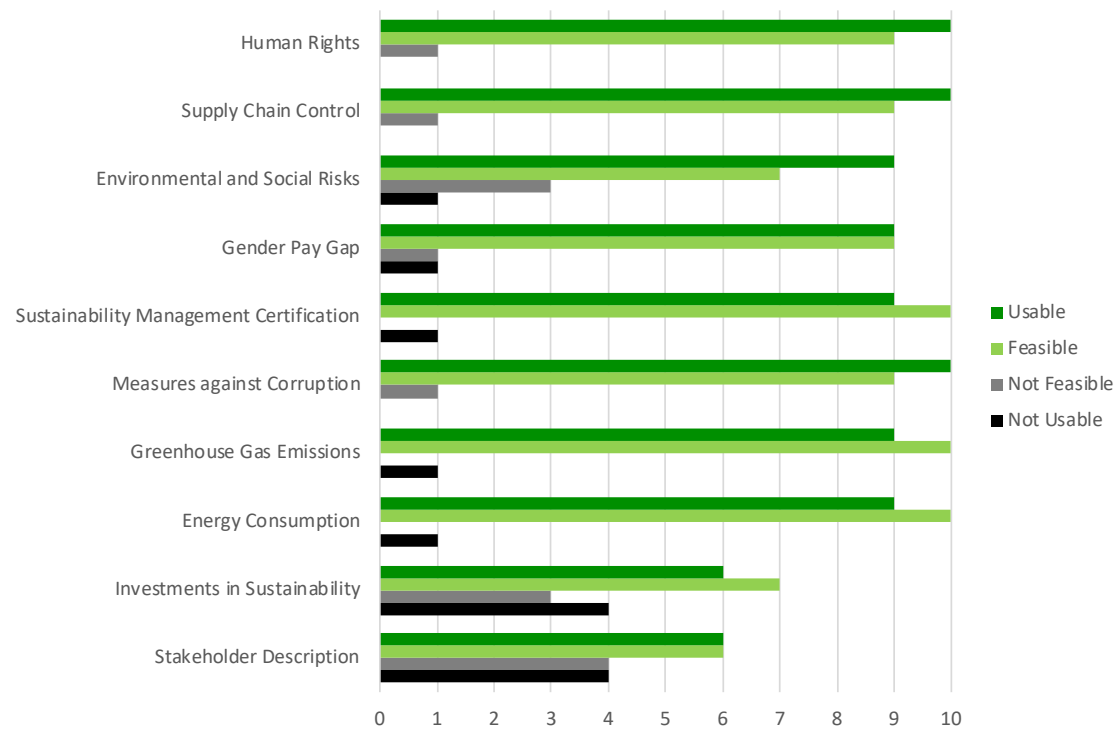

Figure 3: Results of the expert survey

The results and findings conclude with a set of generic criteria framing SPP deductively from existing sustainability measurement knowledge. Swiss procurements experts validate the general feasibility and usability of the SPP frame. This result however is not generalizable, as the cultural context of Switzerland as a direct democracy with a high appreciation of individual freedom allows more for a flexible and generic indicator set, compared to other indicator and procurement regimes, where the criteria are explicitly narrowed down to precise terminology and specifications, so that the procurer is more following prescriptions. In the case of the generic criteria proposed here, the role of the procurer as decision maker is valued and respected, whereas the administrative scaffold of detailed criteria allows for more automated selections by procurers. The next chapter provides practical implications of the SPP frame.

\section{Practical Implications}

The public procurers can work freely within the proposed SPP frame. They do not depend on tick a box obligation but can tailor SPP to their procurement needs in the initial sense of sustainability. The procured products and services constantly change as well as the means to measure sustainability performance. Hence, the proposed generic criteria frame provides an orientation and guideline for professionals and academics alike which leaves enough room to adopt to changes. Procurers can use the generic criteria frame and can select the relevant generic criteria for each tender process. Further, the public procurers can choose dependently on the sustainability relevance of each product or service the best fitting sustainability measurement in form of established criteria within the reach of each generic criteria. Ideally, a tool to choose the right criteria within each generic criteria complements this proposed approach. So, public procurers can always use within the frame the actual and best working methods to operationalize SPP without losing the focus or actuality of sustainability measurement. 
For example, a decision tree or simple algorithm in addition to the presented generic criteria frame allows practitioners to choose the relevant generic criteria in a first step as well as the concerning and needed procurement criteria in a second step. The advantage of such an approach for procurers lies in their empowerment to use sustainability measurement independently instead of using too general and mandated criteria not fitting their needs. The idea of the proposed approach entails that procurers acquire the necessary sustainability knowledge to select generic criteria and procurement criteria for their tendering.

With an accepted frame of SPP consisting of clear and operationalizable ten generic criteria we aim to reduce not only perceived complexity and a facilitated knowledge dissemination of SPP but also the risk aversion of procurers and their leadership. Additionally, we accredit the derived framing for SPP a trigger effect for policy implementation and national goal settings. Of course, the proposed approach contains certain risks. Hence, we recommend to all applicants of the generic criteria to keep in mind their limitations by aggregating complexity into digestible pieces and urge to cautiousness from oversimplification and greenwashing. We urge users and applicants of the provided frame not to hide behind or misuse the inherent latitudes and flexibilities but to use them as chance to tailor sustainability measurement to individual procurement needs, in order to improve them on the long run. The recent "Monte-Ceneri" case about a railway tunnel project in the Alpes, out of the legal public procurement realm from Switzerland, underlines latter and highlights also the importance to transparently choose fitting methodologies for relevant sustainability performance comparisons (Swiss Constitutional Court, 2018). Hence, we suggest to use the SPP frame always entirely with a narrative inclusion and explained reason when omitting a generic criteria to achieve a transparent tender process.

In summary, the proposal of a generic criteria frame empowers public procurers and enhances their importance within the public procurement process, since the decision which sustainability criteria to include with which methods resides with each public procurer. The advantage of the proposed approach lies within its proven usability in other realms of sustainability performance comparison. Thus, the required sustainability measurements and knowledge exists already within the tender participating companies and the public procurer just needs to call up the existing sustainability measurement for comparison.

\section{Discussion and Contribution}

With our research we aim to support current attempts to frame, harmonize and typologyze SPP.

So far studies in SPP concentrated on finding types and frames of SPP inductively out of actual tender processes of the last years (Grandia and Kruyen, 2020). We chose a different way in order to frame SPP by relying on existing SIs and their usage indication for SPP. The resulting SPP frame provides practitioners and researchers alike a guideline to implement and structure SPP.

The presented research in this paper contributes to the theoretical body of public procurement first of all a knowledge transfer from CSR reporting and sustainability performance measurement to SPP. Further, with the concrete elaboration of a generic criteria frame, the proposed approach complements other initiatives like the ISO 20400 which lack a neat set of clear and operational generic criteria. In doing so the research provides an overarching SPP frame for all public purchases without losing itself in individual and detailed requirements of publicly procured goods and services in tender processes. The 
biggest contribution to practice of the presented approach lies in the synergies by relying on existing sustainability measurement information which keeps the additional costs and efforts of tender participating companies at a minimum.

Furthermore, the derived SPP frame includes all three sustainability dimensions as called for by researchers (Grandia and Kruyen, 2020; Grandia and Meehan, 2017; Steiner, 2020), especially the so far rather neglected social dimension. In addition, the paper contributes a SPP frame accepted by experts. We hope the experts' validation supports the agreement on a common ground and understanding for SPP. Another contribution to theory of the paper lies in its aim to find an answer in accordance with current research around the question of how to compare sustainability in public procurement as well as how to frame, type, and define SPP. Current attempts to implement sustainability in public procurement remain rather unstructured without a common all dimensions including understanding of sustainability (Alhola et al., 2019; Bernal et al., 2019; Grandia and Kruyen, 2020; Grandia and Meehan, 2017; Grandia and Voncken, 2019; Sönnichsen and Clement, 2020).

In doing so the paper enhances the position of public procurers in tender processes by relying on their expertise to tailor sustainability into the individual public procurement needs within a frame. On the other side such freedom comes along with responsibilities and mandates knowledge acquisition about sustainability, frames and tools by public procurers. With its derived SPP framing the paper contributes to the overcoming of identified implementation barriers like lack of knowledge and complexity as well as fragmentation and silo approaches towards SPP by providing a small set of easy understandable generic criteria. Further, it contributes a directly operationalizable frame building on existing knowledge within and outside the realm of SPP connecting and synergizing it with other areas of sustainability measurement. In doing so it contributes to the finding of ideal sustainability comparisons in public procurement tenders. The findings of this study deliver a frame of operation. Such an approach needs selection tools of sustainability criteria and SIs' parameters to reach a state of operationalization. The section "practical implications" outlines how such tools might look alike.

Finally, the paper contributes an own definition of Sls which supports the connection of SPP with CSR and aims to bring the worlds of Sls and sustainable procurement criteria together to generate synergies. These synergies play an important role for the success of SPP implementation since companies need to align their sustainability strategies in SPP and CSR reporting with overall sustainability strategies.

Regarding the case of SPP in Switzerland where communality and harmonization of the SPP approach remains one of its main challenges, the elaborated SPP framework serves as common ground and a common language, as well as a further step to profoundly implement sustainability in public procurement on all organizational levels. Furthermore, we contribute with the derived frame an understanding of SPP including all sustainability dimensions in Switzerland, especially the social one, as called for by Swiss public procurers and researchers (ARE, 2018; BAFU, 2018; Steiner, 2020). Additionally, we aim to support the structuring and goal setting of recent SPP implementation strategies in Switzerland with an expert approved SPP frame to enhance its implementation.

\section{Limitations and Future Research}

The presented research provides a starting point and common ground for further investigations and requires continuous refinements essential in the work of framing SPP. A limitation of the study lies in the legal and country specific contextuality of public 
procurement tender processes. Future studies may elaborate how the produced generic criteria frame complies with upcoming public procurement laws, as well as how to maintain the need of flexibility for the unique requirements concerning sustainability in each tender process. Hereby, the challenge resides in the choosing of "fitting" and "sustainability relevant" sustainability criteria with their underlying methods. Future research may look into how to select the best suiting sustainability measurements within the derived frame in this paper, as well as the means to do so for each procured good and service.

The sample at hand represents another limitation. In this regard we want to mention that we have built this study on a high level expert sample including federal and cantonal core experts, also from the side of the judicative. Another limitation of the study can be seen in its methodological approach of deductively assessing existing SIs in their usability for SPP. In doing so it neglects innovative own developments in SPP like life-cycle and life-cycle costing approaches or innovation orientated procurement. Further research can elaborate of how to combine recent inductive and the presented deductive approach of framing SPP in order to produce an upgraded SPP frame and understanding. 


\section{References}

Alhola, K., Ryding, S., Salmenperä, H. and Busch, N.J. (2019), "Exploiting the potential of public procurement: Opportunities for circular economy", Journal of Industrial Ecology, Wiley Online Library, Vol. 23 No. 1, pp. 96-109.

ARE. (2018), CSR: Der Bund Als Beschaffer, Bern.

Arrowsmith, S. and Anderson, R. (2011a), Perspective of the Chairman of the WTO Committee on Government Procurement, Nicholas Niggli (Switzerland), Cambridge: Cambridge University Press, available at:https://doi.org/10.1017/CBO9780511977015.002.

Arrowsmith, S. and Anderson, R. (2011b), The WTO Regime on Government Procurement: Challenge and Reform, WTO, Cambridge University Press, Cambridge.

BAFU. (2018), Instrumente Für Eine Nachhaltige Öffentliche Beschaffung: Gap-Analyse Und Handlungsfelder, Zürich.

Barnett, J., Lambert, S. and Fry, I. (2008), "The Hazards of Indicators: Insights from the Environmental Vulnerability Index", Annals of the Association of American Geographers, Taylor \& Francis Group, Vol. 98 No. 1, pp. 102-119.

Basri, N.H., Noor, N.L.M., Adnan, W.A.W., Saman, F.M. and Baharin, A.H.A. (2016), "Conceptualizing and understanding user experience", 2016 4th International Conference on User Science and Engineering (i-USEr), IEEE, pp. 81-84.

Baue, B. (2019), Compared to What? A Three-Tiered Typology of Sustainable Development Performance Indicators - From Incremental to Contextual to Transformational (Working Paper), Geneva.

Bell, S. and Morse, S. (2003), Measuring Sustainability: Learning from Doing, Routledge, London.

Bell, S. and Morse, S. (2018a), Routledge Handbook of Sustainability Indicators, edited by Bell, S. and Morse, S., Routledge.

Bell, S. and Morse, S. (2018b), "Sustainability Indicators Past and Present: What Next?", Sustainability, Multidisciplinary Digital Publishing Institute, Vol. 10 No. 5, p. 1688.

Bernal, R., San-Jose, L. and Retolaza, J.L. (2019), "Improvement Actions for a More Social and Sustainable Public Procurement: A Delphi Analysis", Sustainability, Multidisciplinary Digital Publishing Institute, Vol. 11 No. 15, p. 4069.

BFS. (2018), "Das MONET 2030-Indikatorensystem", Schweizer Eidgenossenschaft Bundesamt Für Statistik, available at: https://www.bfs.admin.ch/bfs/de/home/statistiken/nachhaltige-entwicklung/monet2030.html (accessed 25 October 2019).

Brammer, S. and Walker, H. (2011), "Sustainable procurement in the public sector: an international comparative study", International Journal of Operations \& Production Management, Vol. 31 No. 4, pp. 452-476.

Bratt, C., Hallstedt, S., Robèrt, K.H., Broman, G. and Oldmark, J. (2013), "Assessment of criteria development for public procurement from a strategic sustainability perspective", Journal of Cleaner Production, Elsevier Ltd, Vol. 52, pp. 309-316.

Bravo, G. (2014), "The Human Sustainable Development Index: New calculations and a first critical analysis", Ecological Indicators, Elsevier, Vol. 37, pp. 145-150.

Cheng, Wenjuan, Andrea Appolloni, Alessio D'Amato, Qinghua Zhu (2018), Green Public Procurement, Missing Concepts and Future Trends - A Critical Review, Journal of Cleaner Production. Volume 176, Pages 770-784

Chowdhury, M.F. (2015), "Coding, sorting and sifting of qualitative data analysis: debates and discussion", Quality \& Quantity, Vol. 49 No. 3, pp. 1135-1143.

Dragos, D.C. and Neamtu, B. (2014), "Sustainable Public Procurement in the EU: Experiences and Prospects", Novelties in the 2014 Directive on Public Procurement, 
Vol. 11 No. 6, pp. 1-26.

EcoVadis. (2017), "EcoVadis CSR Rating Methodology: Overview \& Principles", EcoVadis.

European Commission. (2017), "Green Public Procurement", available at:

http://ec.europa.eu/environment/gpp/index_en.htm (accessed 12 December 2017).

European Union. (2014), Directive 2014/24/EU of the European Parliament and of the

Council of 26 February 2014 on Public Procurement and Repealing Directive 2004/18/EC, Off. J. Eur. Union.

Flynn, A. and Davis, P. (2014), "Theory in public procurement research", edited by Paul, D.Journal of Public Procurement, Emerald Publishing Limited, Vol. 14 No. 2, pp. 139 180.

Gelderman, C.J., Semeijn, J. and Bouma, F. (2015), "Implementing sustainability in public procurement: The limited role of procurement managers and party-political executives", Journal of Public Procurement, Emerald, Vol. 15 No. 1, pp. 66-92.

Given, L.M. (2008), "Typological Analysis", The Sage Encyclopedia of Qualitative Research Methods, Sage Publications.

Goodman, L.A. (1961), "Snowball Sampling", The Annals of Mathematical Statistics, Institute of Mathematical Statistics, Vol. 32 No. 1, pp. 148-170.

Grandia, J. (2015), Implementing Sustainable Public Procurement: An Organisational Change Perspective, edited by Sciences, E.S. of S. and B., Erasmus University Rotterdam.

Grandia, J. (2016), "Finding the missing link: examining the mediating role of sustainable public procurement behaviour", Journal of Cleaner Production, Elsevier, Vol. 124, pp. 183-190.

Grandia, J. (Jolien) and Kruyen, P.M. (Peter). (2020), "Assessing the implementation of sustainable public procurement using quantitative text-analysis tools: A large-scale analysis of Belgian public procurement notices", Journal of Purchasing and Supply Management, p. 100627.

Grandia, J. and Meehan, J. (2017), "Public procurement as a policy tool: using procurement to reach desired outcomes in society", International Journal of Public Sector Management, Emerald Publishing Limited, Vol. 30 No. 4, pp. 302-309.

Grandia, J. and Voncken, D. (2019), "Sustainable public procurement: the impact of ability, motivation, and opportunity on the implementation of different types of sustainable public procurement", Sustainability, Multidisciplinary Digital Publishing Institute, Vol. 11 No. 19 , p. 5215.

GRI. (2019), "GRI Standards", Global Reporting Initiative, available at: https://www.globalreporting.org/standards/gri-standards-download-center/ (accessed 25 October 2019).

Helbing, D. (2013), "Globally networked risks and how to respond", Nature, Nature Publishing Group, a division of Macmillan Publishers Limited. All Rights Reserved., Vol. 497, p. 51.

Hinkel, J. (2011), "Indicators of vulnerability and adaptive capacity: Towards a clarification of the science-policy interface", Global Environmental Change, Vol. 21 No. 1, pp. 198-208.

ISO. (2010), "ISO 26000", International Organization for Standardization, available at: https://www.iso.org/obp/ui/\#iso:std:iso:26000:ed-1:v1:en (accessed 25 October 2019).

ISO. (2017), ISO 20400, Geneva.

Jesinghaus, J. (2018), "How Evil is Aggregation? Lessons from the Dashboard of Sustainability", in Bell, S. and Morse, S. (Eds.), Routledge Handbook of Sustainability Indicators, Routledge, London.

Kluge, S. (2000), "Empirically Grounded Construction of Types and Typologies in Qualitative Social Research", Forum: Qualitative Social Research, Vol. 1 No. 1, p. Art. 
14.

Knebel, S. and Seele, P. (2015), "Quo vadis GRI? A (critical) assessment of GRI 3.1 A+ non-financial reports and implications for credibility and standardization", Corporate Communications: An International Journal, Vol. 20 No. 2, pp. 196-212.

Knebel, S., Stürmer, M., De Rossa Gisimundo, F., Hirsiger, E. and Seele, P. (2019), 9.5 Trillion USD for Sustainability: A Literature Review on Sustainable Public Procurement (Working Paper), available at:https://doi.org/10.13140/RG.2.2.36358.22089.

Koala, K. and Steinfeld, J. (2018), "Theory building in public procurement", Journal of Public Procurement, Emerald, Vol. 18 No. 4, pp. 282-305.

Mahmood, F., Adnan, W.A.W., Noor, N.L.M. and Saman, F.M. (2018), "Emotional Response Towards Cultural-Based E-Government Portal Design Using Card Sorting Method", International Conference on User Science and Engineering, Springer, pp. 12-22.

McCrudden, C. (2004), "Using public procurement to achieve social outcomes", Natural Resources Forum, Vol. 28 No. 4, pp. 257-267.

McCue, C. and Prier, E. (2008), "Using agency theory to model cooperative public purchasing", edited by Eric, P.Journal of Public Procurement, Emerald Publishing Limited, Vol. 8 No. 1, pp. 1-35.

McElroy, M.W. (2019), Making Materiality Determinations - A Context-Based Approach (Working Paper), Geneva.

Meehan, J. and Bryde, D. (2011), "Sustainable procurement practice", Business Strategy and the Environment, Wiley, Vol. 20 No. 2, pp. 94-106.

Morse, S. (2015), "Developing Sustainability Indicators and Indices", Sustainable Development, Wiley, Vol. 23 No. 2, pp. 84-95.

OECD. (2015), "Public Procurement", available at: http://www.oecd.org/gov/publicprocurement/ (accessed 17 December 2017).

Patrucco, A.S., Luzzini, D. and Ronchi, S. (2017), "Research perspectives on public procurement: Content analysis of 14 years of publications in the journal of public procurement", Journal of Public Procurement, Emerald, Vol. 17 No. 2, pp. 229-269.

Preuss, L. (2009), "Addressing sustainable development through public procurement: the case of local government", Supply Chain Management: An International Journal, Vol. 14 No. 3, pp. 213-223.

Prier, E., Schwerin, E. and McCue, C. (2016), "Implementation of sustainable public procurement practices and policies: A sorting framework", Journal of Public Procurement, Vol. 16 No. 3, pp. 312-346.

Salathé-Beaulieu, G., Bouchard, M.J. and Mendell, M. (2019), Sustainable Development Impact Indicators for Social and Solidarity Economy - State of the Art (Working Paper), Geneva.

Schmettow, M. and Sommer, J. (2016), "Linking card sorting to browsing performance-are congruent municipal websites more efficient to use?", Behaviour \& Information Technology, Taylor \& Francis, Vol. 35 No. 6, pp. 452-470.

Smith, C. and Terman, J. (2016), "Overcoming the barriers to green procurement in the county: Interest groups and administrative professionalism”, Journal of Public Procurement, Emerald, Vol. 16 No. 3, pp. 259-285.

Sönnichsen, S.D. and Clement, J. (2020), "Review of green and sustainable public procurement: Towards circular public procurement", Journal of Cleaner Production, Elsevier, Vol. 245, p. 118901.

Steiner, M. (2017), Die Berücksichtigung Sozialer Aspekte Im Rahmen Der Öffentlichen Beschaffung, Bern.

Steiner, M. (2020), "Kurzabriss zu Entstehungsgeschichte und Zwecksetzung des BöB vom 21. Juni 2019", Zeitschrift Für Baurecht Und Vergabewesen, No. 1, pp. 6-8. 
Suziedelis, A. and Lorr, M. (1973), "Occupational differentiation by typological analysis", Journal of Vocational Behavior, Vol. 3 No. 3, pp. 367-374.

Swiss Constitutional Court. (2018), "Auszug aus dem Urteil der Abteilung II i.S. X. AG gegen Schweizerische Bundesbahnen B-4387/2017 vom 8. Februar 2018”, available at: https://jurispub.admin.ch/publiws/pub/search.jsf (accessed 3 February 2020).

Thai, K. (2001), "Public procurement re-examined", Journal of Public Procurement, Emerald Publishing Limited, Vol. 1 No. 1, pp. 9-50.

Thai, K. V. (2008), International Handbook of Public Procurement, edited by Thai, K. V, CRC Press.

The World Bank. (2016), "Despite progress, transparent and efficient government procurement rules remain a global challenge: WBG report", Press Release, available at: http://www.worldbank.org/en/news/press-release/2016/12/05/despite-progresstransparent-and-efficient-government-procurement-rules-remain-a-global-challengewbg-report (accessed 19 December 2017).

Thomas, D.R. (2006), "A General Inductive Approach for Analyzing Qualitative Evaluation Data", American Journal of Evaluation, SAGE Publications Inc, Vol. 27 No. 2, pp. 237-246.

Turnhout, E., Hisschemöller, M. and Eijsackers, H. (2007), "Ecological indicators: Between the two fires of science and policy", Ecological Indicators, Vol. 7 No. 2, pp. 215-228.

UN DESA. (2019), "SDG Indicators", United Nations Department of Economic and Social Affairs.

UN Global Compact. (2019), "The Ten Principles of the UN Global Compact”, United Nations Global Compact, available at: https://www.unglobalcompact.org/what-isgc/mission/principles (accessed 25 October 2019).

UNEP. (2012), Sustainable Public Procurement Implementation Guidelines, Geneva.

UNEP. (2017), "Indicators of Success: Demonstrating the shift to Sustainable Consumption and Production", United Nations Environment Programme.

Uyarra, E. and Flanagan, K. (2010), "Understanding the Innovation Impacts of Public Procurement”, European Planning Studies, Routledge, Vol. 18 No. 1, pp. 123-143.

Walker, H. and Brammer, S. (2009), "Sustainable procurement in the United Kingdom public sector", Supply Chain Management: An International Journal, Emerald Group Publishing Limited, Vol. 14 No. 2, pp. 128-137.

World commission on environment and development. (1987), Our Common Future, Oxford University Press London, Oxford, UK.

WTO. (2012), "Revised Agreement on Government Procurement", available at: https://www.wto.org/english/docs_e/legal_e/rev-gpr-94_01_e.htm (accessed 19 December 2017).

WTO. (2015), "Government Procurement Agreement: Opening markets and promoting good governance".

Zimmerman, D.E. and Akerelrea, C. (2002), "A group card sorting methodology for developing informational web sites", Proceedings. IEEE International Professional Communication Conference, IEEE, pp. 437-445. 